\title{
Effect of social interaction in development of cognitive abilities of dairy animals- A Review
}

\author{
Komal $^{1}$, Sweety ${ }^{2}$, Veenesh Rajpoot $^{3}$ and Man Singh ${ }^{1^{*}}$ \\ ${ }^{1}$ Department of Livestock Production Management, LUVAS, Hisar, India \\ ${ }^{2}$ Department of Veterinary Physiology \& Biochemistry, LUVAS, Hisar, India \\ ${ }^{3}$ Livestock Production Management, National Dairy Research Institute, Karnal, India \\ *Corresponding author
}

\section{Keywords}

Calves, cognition, interaction, social, weaned

\section{Article Info}

Accepted:

20 January 2020

Available Online:

10 February 2020

\section{A B S T R A C T}

\begin{abstract}
Standard practice in the dairy industry is to separate the calf and dam immediately after birth and raise calves in individual pens during the milk-feeding period. But this practice is disputed because of animal welfare concerns. The weaned calves are often offered colostrums/milk in buckets, teat bucket or bottles which does not always satisfy the calf's motivation to suckle. Social isolation early in life impair cognition aspects. Cognition is the mental process of knowing through perception or reasoning. Negative effects of social deprivation early in life also have been shown in adulthood, which include impaired maternal care, increased aggression, and impaired social recognition. Social deprivation can influence neural development and brain function as well as behavior. Dairy cattle, are often exposed to novel events, such as changes in diet, changes in pen location, regrouping with new social partners, and new milking procedures. Therefore cognitive abilities e.g. learning and retention abilities by animals makes it easier to train the animals to use new devices and reallocation of preferred areas to rest, recognition of stock people by dairy animals helps in decrease of animal's fear of stock people, greater ease of handling and less negative interference in the production. Cattle are naturally social and show signs of fear and distress when separated from their companions. Individually housed calves exhibit more non-nutritive behavior than do paired or group-housed calves are slower to start feeding when introduced into a new pen and therefore gain less weight in the days after grouping. So, social experience early in life of calf can have profound effects on affective and cognitive development, ultimately affecting calf welfare and growth as well as calf responses to novel events.
\end{abstract}

\section{Introduction}

Shortly before parturition, cows tend to separate themselves from the herd and give birth in a secluded area (Lidfors et al., 1994). Once the calf is born, a series of maternal behaviors are observed, including licking of the calf and specific vocalizations (Keyserlingk and Weary, 2007). The newborn calf completely depends on the milk provided by the dam and will nurse approximately 8 to 12 times daily with each 
suckling bout lasting approximately $10 \mathrm{~min}$ during the first week of life (Reinhardt and Reinhardt, 1981; Day et al., 1987; Lidfors, 1996). After few days, the calf and mother reintegrate into the herd (Bouissou et al., 2001). Calf starts to increase the distance from the dam from second week of life and starts interacting with peers, and sometimes may form small groups with other calves (Vitale et al., 1986; Sato et al., 1987).

Calves that are reared with their dams and other conspecifics start grazing and ruminating at approximately $3 \mathrm{wk}$ of age and graze regularly with the herd at 3 to 6 months of age (Reinhardt and Reinhardt,1981; Vitale et al., 1986). Calves reared without dam contact had higher heart rate than calves reared with cow-contact at beginning of trial but heart rate of calves was similar at end of trial $\left(F_{2,99}=5.39, P=0.006\right)$ (Buchli et al., 2016). They further investigated that during confrontation phase, calves reared without cow-contact approached the unfamiliar cow more often than calves reared with cowcontact $\left(F_{1,27}=12.22, P=0.002\right)$.

Calves that were reared without dam-contact less often displayed a response to threatening behavior of the cow compared with calves reared with cow-contact $\left(F_{1,26}=14.77, P<\right.$ 0.001) i.e. threatening behavior of the cow caused calves reared with cow-contact to display submissive behavior more often than calves reared without cow-contact $\left(F_{1,26}=\right.$ 16.94, $P<0.001)$. So from above it is concluded that rearing with cow-contact affected the cardiac stress reaction which lead to a more adaptive social behavior compared with traditional rearing without cow-contact.

The succession from maternal care to independence is an important period of learning for young foragers (Provenza and Balph,1987), and there is a influence of peermates on diet selection by young ruminants (Nolte et al., 1990; Provenza et al., 2003).

In summary, as we know ruminants are social animals they start making social relationships starting from birth, initially with the dam and then with other individuals. Also during the milk-feeding period, the calf relies on social cues from the dam and other conspecifics that influence behavioral development. In contrast social isolation has potential negative effects on social and feeding behaviors and future production and performance of animals. In addition to the effects outlined above, social isolation may have important effects on cognitive development of calves.

\section{Social interactions and animal's cognition ability/performance}

Animal cognition refers to the mechanisms by which animals acquire, process, store and act on information from the environment (Shettleworth, 2001). Cognition includes perception, learning, memory and decision making, in short, all ways in which animals take in information about the world through the senses, process, retain and decide to act on it. Such processes play an important role in dealing with their physical and social environments (Shettleworth, 2001).

\section{History of development of science of animal cognition}

Two monumental moments in the history of human thought place the study of animal behavior and learning squarely at the forefront of philosophical and scientific inquiry:

- Descartes's distinction between humans and brutes

- Charles Darwin's hypothesization of mental continuity between human beings and non-human animals. 
Descartes (1637/1994) believed that human beings were fundamentally different from brutes. They had intricate bodily mechanisms that controlled their physiology and behavior, but they lacked what humans alone possessed a rational soul. Descartes believed that animals were incapable of using words or other signs to declare their thoughts to others, if indeed they had any such thoughts, and that animals were bound to respond innately, without the intervention of intelligence.

Against this backdrop of Cartesian thinking, Darwin made evolutionary proposal that humans and animals were not fundamentally different from one another nor did they have different origins. In stark contrast to Descartes, Darwin viewed both communication and intelligence from a natural scientific perspective; rudimentary antecedent or even highly advanced forms of each of these behavioral abilities were to be found throughout the animal kingdom, thus disclosing mental continuity between human and non-human animals. As Domjan (1987) observed that Darwin's ideas made the study of animal behavior relevant to, and in fact crucial to, the understanding of human behavior.

\section{Basis of learning in animals}

\section{Associative learning - pavlovian conditioning or classical conditioning}

Classical conditioning is a form of associative learning where a conditioned stimulus (biologically neutral) is paired with an unconditioned stimulus (biologically potent) which leads to an involuntary unconditioned response (UR) from the animal.

After repeated exposure the behavioral response can be induced by the CS alone. For example, the action of being milked (US) is linked to the milk let down response (UR).
After a few milkings, milk let down is often induced by simply entering the milking parlour or even the crowd pen (CS) (Willis and Mein, 1983).

\section{Instrumental conditioning}

Operant conditioning is a process of behavioral modification in which the likelihood of a specific behavior is either increased or decreased using reinforcement or punishment, respectively. Cattle approaching a milking unit of an automatic milking system in response to an auditory cue used to give food as a reward (Wredle et al., 2006)

In this study a small box emitting an acoustic signal was attached to a collar on each cow and cows were rewarded for visiting the target area in response an audio cue.

\section{Effect of social isolation on the dairy calves}

Calves typically provided little or no social contact on dairy farms showing detrimental effects of isolation. Evidence suggests that socially reared calves are less fearful (Boe and Farevik, 2003) and more dominant when mixed in groups later in life (Veissier et al., 1994) compared with calves that have been reared in isolation. Several factors play a role in social behavior development, such as age of first contact with conspecifics and level of contact.

For instance, calves allowed full social contact with another calf, either from birth or from 3 wk of age, established a stronger bond compared with calves raised with only visual or auditory contact with other calves (Duve and Jensen, 2011). Calves housed individually or with only limited contact were more fearful than pair-housed calves (Jensen and Larsen, 2014). Collectively, this evidence suggests that full social contact with peers from an early age is important for the calf. 
Table.1 Effect of social housing on behavior of calves

\begin{tabular}{|c|c|c|c|c|}
\hline Treatment & Animals & Parameter & Effect of socialization & Reference \\
\hline $\begin{array}{l}\text { Individual;complex } \\
\text { ( } \leq 8 \text { calves }+ \text { night access } \\
\text { to cows) }\end{array}$ & Bull calves & Intake of unfamiliar feed type & $\begin{array}{l}\text { Complex housed calves had more } \\
\text { intake of unfamiliar feed type }\end{array}$ & Costa et al., 2014 \\
\hline Individual;pairs & Female calves & $\begin{array}{l}\text { Vocalization after teat } \\
\text { removal }\end{array}$ & $\begin{array}{l}\text { Pair housed calves had less } \\
\text { vocalization after teat removal }\end{array}$ & Vieira et al., 2010 \\
\hline Individual;pairs & Female calves & $\begin{array}{l}\text { Latency to feed in novel } \\
\text { environment }\end{array}$ & $\begin{array}{l}\text { Pair housed calves had less } \\
\text { latency to approach feed }\end{array}$ & Vieira et al., 2010 \\
\hline Individual;pairs & Female calves & $\begin{array}{l}\text { Intake of feed after being } \\
\text { moved to a new environment }\end{array}$ & $\begin{array}{l}\text { Pair housed calves had more } \\
\text { intake of feed }\end{array}$ & Vieira et al., 2010 \\
\hline Individual;pairs & $\begin{array}{l}\text { Female and bull } \\
\text { calves }\end{array}$ & Social behavior & $\begin{array}{l}\text { Pair housed calves performed } \\
\text { more social behaviors }\end{array}$ & Duve et al., 2012 \\
\hline Individual ;group & Heifers & $\begin{array}{l}\text { Avoidance of unfamiliar } \\
\text { calves }\end{array}$ & $\begin{array}{l}\text { Group housed more interactive } \\
\text { with unfamiliar calves }\end{array}$ & Jenson et al., 1997 \\
\hline Individual ;group & Heifers & Fear in open field test & $\begin{array}{l}\text { Group housed heifer less fearful } \\
\text { in open field test }\end{array}$ & Jenson et al., 1997 \\
\hline Individual;pair & $\begin{array}{l}\text { Female and bull } \\
\text { calves }\end{array}$ & Playing behavior & Both showed equal play behavior & Jenson et al., 2015 \\
\hline $\begin{array}{l}\text { Individual; group } \\
\text { ( } 4 \text { calves) }\end{array}$ & Bull calves & Aggression at mixing & $\begin{array}{l}\text { Group housed had more } \\
\text { aggressiveness }\end{array}$ & Veissier et al., 1994 \\
\hline $\begin{array}{l}\text { Individual; group } \\
\text { ( } 4 \text { calves) }\end{array}$ & Bull calves & Social rank & $\begin{array}{l}\text { Group housed calves higher in } \\
\text { social ranking }\end{array}$ & Veissier et al., 1994 \\
\hline
\end{tabular}




\section{Group housing of dairy calves}

One benefit of housing calves in groups includes reduced labor requirement per head (Broom and Leaver, 1978). One recent study reported that "reducing labor" and "saving time" were among the main reasons that farmers provided for group-housing dairy calves (Hotzel et al., 2014). The development of automated feeding systems for calves has accelerated adoption of group housing of dairy calves, particularly for larger dairy farms (Kung et al., 1997). There is also increased awareness of animal welfare by both dairy producers and the public, and one important welfare concern is the social isolation of calves (Boogaard et al., 2010; Ventura et al., 2013).

\section{Social support and behavior of calves}

Social buffering is the ability of social partners to decrease the effect of stressors during a challenge (Cohen and Wills,1985). Social buffering has been demonstrated in humans (Thorsteinsson et al., 1998), rats (Kiyokawa et al., 2014a), guinea pigs (Hennessy et al., 2000), pigs (Reimert et al., 2014), and other farm animals (Rault, 2012). For example, the work on rats has shown a decreased response to stressors in the presence of others (Hennessy et al., 2000; Kiyokawa et al., 2014a), especially familiar conspecifics (Kiyokawa et al., 2014b). In cattle, the presence of conspecifics is known to reduce behavioral reactions to social separation (Boissy and Le Neindre, 1997; Piller et al., 1999). For example, calves vocalize less in a novel arena when in companionship with familiar calves compared with when they are placed with unfamiliar calves (Farevik et al., 2006). There is also some evidence of social buffering in calves in response to a nonsocial stressor; individually housed calves show a stronger vocal response to weaning from milk compared with paired calves (Vieira et al., 2010). Efficacy of social buffering may be influenced by several factors, including the strength of affiliation between the individuals. As (Bolt et al., 2017) found that calves paired at day 28 exhibited lower number of vocalization as compared to calves paired at day 28 .

\section{Socialization and cognitive behavior of calves}

Social isolation early in life can impair cognition in rodents and other species (Jones et al., 1991; Fone and Porkess, 2008). Socially isolated rodents showed deficits in reversal learning (Jones et al., 1991), a method often used to assess behavioral flexibility in animals (Fone and Porkess, 2008). The study was conducted to examine reversal learning in pair-housed and individually housed calves. They found that individually housed calves reached the criteria after 15 training sessions and pair housed calves after 12 sessions $(\mathrm{Z}=21.10, \mathrm{p}=0.27)$. When the training stimuli were reversed, calves in both treatments performed poorly. The median number of sessions needed to reach this criterion was 19.5 for the individually housed calves versus 13.0 for the paired calves $(\mathrm{Z}=20.94, \mathrm{p}=0.34)$ (Gaillard et al., 2014). Daros et al., 2014 studied the influence of separation from dam on the responses of dairy calves in a discrimination task between red and white colours and they found that the go responses to the screen was $72 \pm 3.6 \%$ before separation but declined to $62 \pm 3.6 \%$ after separation from the dam.

A follow up study reported that during discrimination phase, there was no difference between group $(8.9 \pm 0.9$ training sessions) and individually housed (10.6 \pm 0.6 sessions) treatments in learning speed $\left(\mathrm{t}_{13}=1.49, \mathrm{p}=\right.$ $0.16)$. But in the reversal phase, seven of the eight group calves were able to reach the learning criterion taking $10.3 \pm 2.4$ sessions 
whereas only one out of seven calves reached the criterion in the individual treatment (Fisher-exact test; $p=0.01$ ) . Group and calves paired at 6 day of life did not differ in learning the reversal task ( 7 of 9 vs. 9 of 12 calves; $p=0.882$ ). These group termed as early social group. Further 16 of 21 calves of early social groups successfully reached the criterion than did individual i.e. 9 of 12 calves $(p=0.882)$. Late Pair i.e at 6 week of life had intermediate success (7 of 12 calves), not differing from Early Social calves, but tending to be higher than that for Individual calves $(p=0.099)$ (Meagher et al., 2015).

In the latter study, it was concluded that the majority of individually housed calves did not learn the reversal task even when provided twice as many sessions as required by the average socially housed calf. Similar results have been reported in rodents, and these studies indicate that the cognitive deficit is associated with decreased brain development and plasticity (e.g., Schrijver and Wurbel, 2001; Fowler et al., 2002; Lipkind et al., 2002). In rodents, it is well established that the prefrontal cortex is responsible for behavioral control, decision-making, and inhibition of behavior (Dalley et al., 2004). These controls are essential for success in reversal learning.

Costa et al., (2014) found that dam reared calves, when tested at 10 weeks of age, tasted novel feed sooner after introduction of the food and ate more of it, compared to calves individually reared. Calves weaned for less than 2 weeks were faster in changing a learned route in a maze compared to those which were weaned for longer (Veissier et al., 1989).

So from above review it was concluded that calves housed with social companions from an early age, either in a complex social environment (either with the presence of their dam and other cows and calves) or simply pair-housed, performed better in reversal learning than did individually reared calves indicating impaired behavioral flexibility in socially deficit calves.

\section{Calves coping with novelty in social life}

Farm animals, including dairy cattle, are more often exposed to novel events, such as changes in diet, changes in pen location, regrouping with new social partners, and new milking procedures.

Calves reared in groups were more social confident and show less fear than calves reared individually or in isolation (Bøe and Faerevik., 2003). Individually reared calves show greater reactivity to environmental novelty compared with socially reared animals. Veissier et al., 1997 showed that isolation of calves promoted reactiveness to startling stimuli and development of selfdirected oral behaviors. Calves housed individually for the first 3 month of life were more reactive to environmental and social novelty than group-housed animals when tested at $90 \mathrm{~d}$ of age (Jensen et al., 1997).

Vieira et al., 2012 reported that during the social novelty test with unfamiliar calf, calves housed individually spent less time running (51.8 vs. $96.4 \pm 11.6 \mathrm{~s} /$ test $)$, found a longer latency to socially interact (111.1 vs. $20.4 \pm 21.7$ s/test), and spent more time involved in social interactions (130.7 vs. $79.7 \pm 19.0 \mathrm{~s} /$ test $)$ than did pair-housed calves. As compared to pair housed calves, individually housed calves were also more reactive to the presence of an unfamiliar calf as indicated by increased rates of defecation ( 2.3 vs. $0.7 \pm 0.5$ events/test) and kicking (2.2 vs. $0.7 \pm 0.4$ events/test). Further Gaillard et al., 2014 observed that housing treatment did not influence time spent exploring the object in the first session $(t=20.18$, d.f. $=11, p>0.10)$, 
which averaged $55.4 \pm 22.2 \mathrm{~s}$ for individual calves and $50.9 \pm 12.2 \mathrm{~s}$ for pair calves. But latter on pair-housed calves significantly reduced their time spent exploring with repeated testing $\left(\mathrm{F}_{1,69}=4.74, \mathrm{p}=0.033\right)$ whereas individually-housed calves showed no significant decline in time spent exploring the object over repeated sessions $\left(\mathrm{F}_{1,55}=0.08\right.$, $\mathrm{p}>0.10)$. So Individually reared calves are more fearful and less willing to originate social interactions whereas group reared calves are more confident around conspecifics and show less fear response to humans (Bøe and Faerevik, 2003).

Buchli et al., 2016 showed that during confrontation phase, calves reared without cow-contact procced towards the unfamiliar cow more often than calves reared with cowcontact $\left(F_{1,27}=12.22, P=0.002\right)$. Calves reared without cow-contact less often showed a response to threatening behavior of cows compared with calves reared with cowcontact $\left(F_{1,26}=14.77, P<0.001\right)$ as they were in regular contact with adult cows and experience broad range of interactions with dam and other adult, including agonistic behaviors like threats and displacements (Waiblinger et al., 2013). Whereas calves reared without cow contacts were less cautious approaching the cow.

Moreover, calves reared with cow-contact showed submissive behavior more often than calves reared without cow-contact $\left(F_{1,26}=\right.$ 16.94, $P<0.001)$ in response to threatening behavior of the cow. Similarly, Wagner et al., (2012) found that dam-reared heifers were more submissive during integration into the cow herd compared with heifers reared without dam-contact. They learned to know social signals of conspecifics and to react in adaptive way as submissive behavior reduce the risk of being attacked.

In contrast, early social contact reduces behavioral and physiological reactivity to environmental novelty. Calves provided social contact showed decreased responses to restraint, increased play during the milk feeding phase, and increased competitive success after weaning (Duve et al., 2012), as well as lower adrenocortical reactivity to stress (Creel and Albright,1988; Raussi et al., 2003).

Abdelfattah et al., 2018 observed that calves housed in groups of 3 at $3^{\text {rd }}$ day $(\mathrm{GH} 3)$ showed more play behavior than calves housed in groups of 3 at $7^{\text {th }}(\mathrm{GH} 7)$ and $14^{\text {th }}$ $\operatorname{day}(\mathrm{GH} 14)\left(F 2,{ }_{189}=6.39, P=0.03\right)$. Play behavior peaked at $3^{\text {rd }}$ week and reduced by $6^{\text {th }}$ week $(P<0.001)$, supporting earlier work of Jensen et al., 1998; Jensen and Kyhn, 2000 and Duve and Jensen, 2011.Calves raised in pairs or in small groups of calves showed lower heart rates when placed in a pen with an unfamiliar calf (Jensen et al., 1997) and were less fearful and more willing to approach unfamiliar calves when mixed after weaning (Vieira et al., 2012a).

Socially reared calves were also less neophobic toward a new food item than calves reared individually (Costa et al., 2014). Horvath et al., 2017 reported that during novel object session, enriched calves found reward faster than control calves (6.11 vs 20.6s; $\mathrm{SE}=4.06 ; \mathrm{P}=0.001$ ) whereas control calves spent longer in the middle of maze where the novel object was located (2.08 vs 13.4s; $\mathrm{SE}=5.33 ; \mathrm{P}=0.04)$.

\section{References}

Abdelfattah, E. M., Karousa, M. M., Lay Jr, D. C., Marchant-Forde, J. N. and Eicher, S. D. (2018). Effect of age at group housing on behavior, cortisol, health, and leukocyte differential counts of neonatal bull dairy calves. Journal of Dairy Science, 101: 596-602. 
Boissy, A. and Le Neindre, P. (1997). Behavioral, cardiac and cortisol responses to brief peer separation and reunion in cattle. Physiology \& Behavior, 61: 693-699.

Bøe, K. E., and Færevik, G. (2003). Grouping and social preferences in calves, heifers and cows. Applied Animal Behaviour Science, 80: 175-190.

Bolt, S. L., Boyland, N. K., Mlynski, D. T., James, R. and Croft, D. P. (2017). Pair housing of dairy calves and age at pairing: Effects on weaning stress, health, production and social networks. PloS one, 12(1), e0166926.

Bouissou, M. F., Boissy, A., Le Neindre, P. and Veissier, I. (2001). The social behaviour of cattle. Social Behaviour in Farm Animals, 113-145.

Boogaard, B. K., Bock, B. B., Oosting, S. J. and Krogh, E. (2010). Visiting a farm: An exploratory study of the social construction of animal farming in Norway and the Netherlands based on sensory perception. International Journal of Sociology of Agriculture and Food, 17: 24-50.

Broom, D. M. and Leaver, J. D. (1978). Effects of group-rearing or partial isolation on later social behaviour of calves. Animal Behaviour, 26: 12551263.

Buchli, C. (2016). Influence of calf-cow contract during rearing on social competence and stress reactivity in calves (Doctoral dissertation, ETH Zurich).

Cohen, S. and Wills, T. A. (1985). Stress, social support, and the buffering hypothesis. Psychological Bulletin, 98: 310.

Costa, J. H. C., Daros, R. R., Von Keyserlingk, M. A. G. and Weary, D. M. (2014). Complex social housing reduces food neophobia in dairy calves. J. Dairy Sci. 97: 7804-7810.
Creel, S. R. and Albright, J. L. (1988). The effects of neonatal social isolation on the behavior and endocrine function of Holstein calves. Appl. Anim. Behav. Sci. 21:293-306.

Daros, A. R., Uliaszek, A. A. and Ruocco, A. C. (2014). Perceptual biases in facial emotion recognition in borderline personality disorder. Personality Disorders: Theory, Research, and Treatment, 5: 79

Day, M. L., Imakawa, K., Clutter, A. C., Wolfe, P. L., Zalesky, D. D., Nielsen, M. K. and Kinder, J. E. (1987). Suckling behavior of calves with dams varying in milk production. J. Anim. Sci., 65: 1207-1212

Descartes, R. (1970). Descartes's philosophical letters (A. Kenny, Ed. and Trans.). Oxford, United Kingdom: Clarendon. (Original work published 1646).

Domjan, M. (1987). Animal learning comes of age. American Psychologist, 42: 556.

Duve, L. R., and Jensen, M. B. (2011). The level of social contact affects social behavior in pre-weaned dairy calves. Appl. Anim. Behav. Sci. 135: 34-43.

Duve, L. R., Weary, D. M., Halekoh, U. and Jensen, M. B. (2012). The effects of social contact and milk allowance on responses to handling, play, and social behavior in young dairy calves. J. Dairy Sci. 95: 6571-6581.

Farevik, G., Jensen, M. B. and Boe, K. E. (2006). Dairy calves social preferences and the significance of a companion animal during separation from the group. Appl. Anim. Behav. Sci., 99: 205-221.

Fone, K. C. and Porkess, M. V. (2008). Behavioural and neurochemical effects of post-weaning social isolation in rodents-relevance to developmental neuropsychiatric disorders. Neuroscience and Biobehavioral 
Reviews, 32: 1087-1102.

Fowler, C. D., Y. Liu, C. Ouimet, and Z. Wang. 2002. The effects of social environment on adult neurogenesis in the female prairie vole. J. Neurobiol. 51: 115-128.

Gaillard, C., Meagher, R. K., von Keyserlingk, M. A. and Weary, D. M. (2014). Social housing improves dairy calves' performance in two cognitive tests. PloS one, 9: e90205.

Hennessy, M. B., Maken, D. S. and Graves, F. C. (2000). Consequences of the presence of the mother or unfamiliar adult female on cortisol, ACTH, testosterone and behavioral responses of periadolescent guinea pigs during exposure to novelty. Psychoneuroendocrinology 25: 619 632.

Horvath, K., Fernandez, M. and MillerCushon, E. K. (2017). The effect of feeding enrichment

in the milk-feeding stage on the cognition of dairy calves in a Tmaze. Applied Animal Behaviour Science, 187: 8-14.

Hotzel, M. J., Longo, C., Balcao, L. F., Cardoso, C. S. and Costa, J. H. C.(2014). A survey of management practices that influence performance and welfare of dairy calves reared in Southern Brazil. PLoS ONE 9: e114995.

Jensen, M. B. and Larsen, L. E. (2014). Effects of level of social contact on dairy calf behavior and health. J. Dairy Sci. 97: 5035-5044.

Jensen, M. B., Vestergaard, K. S., Krohn, C. C. and Munksgaard, L. (1997). Effect of single versus group housing and space allowance on responses of calves during open-field tests. Applied Animal Behaviour Science, 54: 109-121.

Jensen, M. B. and Kyhn, R. (2000). Play behaviour in group-housed dairy calves, the effect of space allowance. Applied
Animal Behaviour Science, 67: 35-46.

Jensen, M. B., Duve, L. R. and Weary, D. M. (2015). Pair housing and enhanced milk allowance increase play behavior and improve performance in dairy calves. $J$. Dairy Sci. 98: 2568-2575.

Jones, G. H., Marsden, C. A. and Robbins, T. W. (1991). Behavioural rigidity and rule-learning deficits following isolation-rearing in the rat: neurochemical correlates. Behavioural Brain Research, 43: 35-50

Kiyokawa, Y., Honda, A., Takeuchi, Y. and Mori, Y. (2014b). A familiar conspecific is more effective than an unfamiliar conspecific for social buffering of conditioned fear responses in male rats. Behav. Brain Res. 267: 189-193.

Kiyokawa, Y., Hiroshima, S., Takeuchi, Y. and Mori, Y. (2014a). Social buffering reduces male rats' behavioral and corticosterone responses to a conditioned stimulus. Horm. Behav. 65: 114-118.

Kung, L., Demarco, S., Siebenson, L. N., Joyner, E., Haenlein, G. F. W. and Morris, R. M. (1997). An evaluation of two management systems for rearing calves fed milk replacer. J. Dairy Sci., 80: 2529-2533.

Lidfors, L. M., Moran, D., Jung, J., Jensen, P. and Castren, H. (1994). Behaviour at calving and choice of calving place in cattle kept in different environments. Applied Animal Behaviour Science, 42: 11-28.

Lidfors, L. M. (1996). Behavioural effects of separating the dairy calf immediately or 4 days post-partum. Appl.Anim. Behav. Sci., 49: 269-283.

Lipkind, D., Nottebohm, R., Rado, R. and Barnea, A. (2002). Social change affects the survival of new neurons in the forebrain of adult songbirds. Behav. Brain Res. 133: 31-43. 
Meagher, R. K., Daros, R. R., Costa, J. H., Von Keyserlingk, M. A., Hötzel, M. J. and Weary, D. M. (2015). Effects of degree and timing of social housing on reversal learning and response to novel objects in dairy calves. PloS one, 10: e0132828.

Nolte, D. L., Provenza, F. D. and Balph, D. F. (1990). The establishment and persistence of food preferences in lambs exposed to selected foods. $J$. Anim. Sci., 68: 998-1002.

Piller, C. A. K., Stookey, J. M. and Watts, J. M. (1999). Effects of mirror-image exposure on heart rate and movement of isolated heifers. Appl. Anim. Behav. Sci. 63: 93-102.

Provenza, F. D. and Balph, D. F. (1987). Diet learning by domestic ruminants: theory, evidence and practical implications. Applied Animal Behaviour Science, 18: 211-232.

Provenza, F. D., Villalba, J. J., Dziba, L. E., Atwood, S. B. and Banner, R. E. (2003). Linking herbivore experience, varied diets, and plant biochemical diversity. Small Rumin. Res. 49: 257-274.

Rault, J. L. 2012. Friends with benefits: Social support and its relevance for farm animal welfare. Appl. Anim. Behav. Sci. 136: 1-14.

Reimert, I., Rodenburg, T. B., Ursinus, W. W., Kemp, B. and Bolhuis, J. E. (2014). Responses to novel situations of female and castrated male pigs with divergent social breeding values and different backtest classifications in barren and straw-enriched housing. Applied Animal Behaviour Science, 151: 24-35.

Raussi, S., Lensink, B. J., Boissy, A., Pyykkonent, M. and Veissier, I. (2003). The effect of contact with conspecifics and humans on calves' behaviour and stress responses. Anim. Welf. 12: 191202.
Reinhardt, V. and Reinhardt. A. (1981). Natural sucking performance and age of weaning in zebu cattle (Bos indicus). J. Agric. Sci. 96: 309-312.

Sato, S., Wood-Gush, D. G. M. and Wetherill, G. (1987). Observations on creche behaviour in suckler calves. Behavioural Processes, 15: 333 343.

Schrijver, N. C. A. and Wurbel, H. (2001). Early social deprivation disrupts attentional, but not affective, shifts in rats. Behav. Neurosci. 115: 437-442.

Shettleworth, S. J. (2001). Animal cognition and animal behaviour. Animal Behaviour, 61: 277-286.

Thorsteinsson, E. B., James, J. E. and Gregg, M. E. (1998). Effects of video-relayed social support on hemodynamic reactivity and salivary cortisol during laboratory-based behavioral challenge. Health Psychology, 17: 436.

Veissier, I., Gesmier, V., Le Neindre, P., Gautier, J. Y. and Bertrand, G. (1994). The effects of

earing in individual crates on subsequent social behaviour of veal calves. Applied Animal Behaviour Science, 41: 199-210.

Veissier, I., Le Neindre, P. and Trillat, G. (1989). The use of circadian behaviour to measure adaptation of calves to changes in their environment. Applied Animal Behaviour Science, 22: 1-12.

Veissier, I., Chazal, P., Pradel, P. and Le Neindre, P. (1997). Providing social contacts and objects for nibbling moderates reactivity and oral behaviors in veal calves. Journal of Animal Science, 75: 356-365.

Ventura, B. A., von Keyserlingk, M. A. G., Schuppli, C. A. and Weary, D. M. (2013). Views on contentious practices in dairy farming: The case of early cowcalf separation. J. Dairy Sci. 96: 61056116. 
Vieira, A. D. P., de Passillé, A. M. and Weary, D. M. (2012a). Effects of the early social environment on behavioral responses of dairy calves to novel events. Journal of Dairy Science, 95: 5149-5155.

Vieira, A. D. P., Von Keyserlingk, M. A. G. and Weary, D. M. (2012b). Presence of an older weaned companion influences feeding behavior and improves performance of dairy calves before and after weaning from milk. Journal of Dairy Science, 95: 3218-3224.

Vieira, A. D. P., Von Keyserlingk, M. A. G. and Weary, D. M. (2010). Effects of pair versus single housing on performance and behavior of dairy calves before and after weaning from milk. Journal of dairy science, 93: 3079-3085.

Vitale, A. F., Tenucci, M., Papini, M. and Lovari, S. (1986). Social behaviour of the calves of semi-wild Maremma cattle, Bos primigenius taurus. Applied Animal Behaviour Science, 16: 217-231.

Von Keyserlingk, M. A. and Weary, D. M. (2007). Maternal behavior in cattle. Hormones Behavior, 52: 106-113.
Waiblinger, S, Wagner, K., Hillmann, E. and Barth, K. (2013). Play and social behaviour of calves with or without access to their dam and other cow. KTBL Current rasearch in Applied Ethology. 503:153-159.

Wagner, K., Barth, K., Hillmann, E., Palme, R., Futschik, A. and Waiblinger, S. (2013). Mother rearing of dairy calves: reactions to isolation and to confrontation with an unfamiliar conspecific in a new environment. Applied Animal Behaviour Science, 147: 43-54.

Wagner, K., Barth, K., Palme, R., Futschik, A. and Waiblinger, S. (2012). Integration into the dairy cow herd: Long-term effects of mother contact during the first twelve weeks of life. Applied Animal Behaviour Science, 141: 117-129.

Wredle, E., Munksgaard, L. and Spörndly, E. (2006). Training cows to approach the milking unit in response to acoustic signals in an automatic milking system during the grazing season. Applied Animal Behaviour Science, 101: 27-39.

\section{How to cite this article:}

Komal, Sweety, Veenesh Rajpoot and Man Singh. 2020. Effect of social interaction in development of cognitive abilities of dairy animals- A Review. Int.J.Curr.Microbiol.App.Sci. 9(02): 2812-2822. doi: https://doi.org/10.20546/ijcmas.2020.902.320 